\title{
Preoperative Valsava Leak Point Pressure May Not Predict Outcome of Mid-Urethral Slings. Analysis from a Randomized Controlled Trial of Retropubic versus Transobturator Mid-Urethral Slings
}

\author{
Elisabetta Costantini, Massimo Lazzeri, Antonella Giannantoni, Vittorio Bini, Alberto Vianello, \\ Ervin Kocjancic, Massimo Porena
}

Department of Medical and Surgical Specialties and Public Health, Section of Urology and Andrology (EC, ML, AG, AV, MP), and Department Internal Medicine (VB), University of Perugia, Perugia, Italy and Department of Urology (EK), University of Udine, Udine, Italy

\begin{abstract}
Objective: To test the hypothesis that preoperative Valsalva leak point pressure (VLPP) predicts long-term outcome of midurethra slings for female stress urinary incontinence (SUI).

Materials and Methods: One hundred and forty-five patients with SUI were prospectively randomized to two mid-urethra sling treatments: Tension free vaginal tape (TVT) or transobturator tape (TOT). They were followed-up at 3, 6, 12 months post-operatively and then annually for the primary outcome variable, i.e. dry or wet and secondary outcome variables such as scores on the urogenital distress inventory (UDI-6) and the impact of incontinence on quality of life (IIQ-7) questionnaire as well as patient satisfaction as scored on a visual analogue scale (VAS). Preoperative VLPP was correlated with primary and secondary outcome variables.

Results: Mean follow-ups were $32 \pm 12$ months (range 12-55) for TVT and $31 \pm 15$ months (range 12-61) for TOT. When patients were analyzed according to VLPP stratification, 95 (65.5\%) patients showed a VLPP > $60 \mathrm{~cm}_{2} \mathrm{O}$ and 50 (34.5\%) patients had a VLPP $\leq 60 \mathrm{~cm} \mathrm{H}_{2} \mathrm{O}$. The overall objective cure rates were $75.8 \%$ for patients with VLPP $>60 \mathrm{~cm} \mathrm{H}_{2} \mathrm{O}$ and $72 \%$ for those with VLPP $\leq 60 \mathrm{~cm} \mathrm{H}_{2} \mathrm{O}(\mathrm{p}<0.619)$. No significant differences in objective cure rates emerged when patients were stratified for pre-operative VLPP and matched for TOT or TVT procedures: VLPP > $60 \mathrm{~cm} \mathrm{H}_{2} \mathrm{O}$ (82\% vs. 68.9\% $\left.\mathrm{p}<0.172\right)$; VLPP $\leq 60 \mathrm{~cm} \mathrm{H}_{2} \mathrm{O}(68 \%$ vs. $76 \% \mathrm{p}<0.528)$.

Conclusions: When patients were stratified for preoperative VLPP $\left(\leq\right.$ or $>$ of $\left.60 \mathrm{~cm} \mathrm{H}_{2} \mathrm{O}\right)$, preoperative VLPP was not linked to outcome after TVT or TOT procedures.
\end{abstract}

Key words: urinary incontinence; Valsalva leak point pressure; tension free vaginal tape; transobturator tape Int Braz J Urol. 2008; 34: 73-83

\section{INTRODUCTION}

Since the tension-free vaginal tape (TVT) procedure was first described by Ulmsten et al. in
1996 (1), mid-urethral sling procedures have been established as safe and effective in the treatment of female stress urinary incontinence (SUI) (2). Longterm follow-ups showed high cure rates ranging from 
$81 \%$ to $95 \%$ for TVT and the recently introduced tension free transobturator tape (TOT) procedures (3 - 6). Although most studies analyzed the safety and the efficacy of mid-urethra slings, outcomes, and the complication rate, a few tried to address the issue of factors predicting long-term outcome.

Urethral integrity was first investigated as outcome predictor in patients who underwent mid urethral sling operations for SUI. Miller et al. found at 3 months after surgery that TOT was nearly 6 times more likely to fail than TVT in subjects with a preoperative maximum urethral closure pressure at or below $42 \mathrm{~cm} \mathrm{H}_{2} \mathrm{O}$ (7). The Valsalva Leak Point Pressure (VLPP), which the International Continence Society (ICS) defined as the intravesical pressure at which urine leakage occurs due to increased abdominal pressure generated by a Valsalva maneuver, is considered an objective parameter for SUI severity (8). In 1993, McGuire et al. demonstrated that leakage pressure during the Valsalva maneuver was a reliable method for assessing the urethral sphincter mechanism (9). These findings were confirmed by Feldner Jr. et al. and Albo et al. $(10,11)$, and indeed Albo et al. concluded that the VLPP might be a good measure of urethral sphincter dysfunction even though it was not associated with symptom severity, quantity of urine loss, or its effect on the patient's Quality of Life (QoL).

Patients with a low VLPP on preoperative urodynamic assessment were reported to have increased risk of treatment failure $(12,13)$. In a recent investigation into preoperative VLPP as a predictor of outcome after distal urethral sling procedures, Rodriguez et al. reported the VLPP was useful for diagnosing SUI, but, at a 14-month follow-up, appeared to be of minimal importance in predicting outcome (14). On the other hand, in patients who underwent midurethra slings, O'Connor reported excellent results in patients with a VLPP $>60 \mathrm{~cm} \mathrm{H}_{2} \mathrm{O}$ but not in those with a low $\operatorname{VLPP}\left(\leq 60 \mathrm{~cm} \mathrm{H}_{2} \mathrm{O}\right)(15)$. As both these studies had short follow-ups and did not match outcomes for different types of surgery, the role of VLPP in predicting the risk of failure at long-term follow-up remains an open issue.

The present study investigated the prognostic value of VLPP for mid-urethral sling outcomes using data from a randomized controlled study of 145 women with stress or mixed urinary incontinence that were treated with either TVT or TOT (16).

\section{MATERIALS AND METHODS}

From May 2002 to November 2005, 145 patients affected by SUI as defined by ICS (8) and who were candidates for the mid-urethral sling procedure were prospectively randomized by a predetermined computer-generated randomization code, to the retropubic approach (TVT) or the transobturator route (TOT). Randomization was done using sealed, opaque, numbered envelopes, which contained the randomized allocation. The Regional Ethics Committee approved the study protocol and all patients gave written informed consent.

Inclusion criteria were stress or mixed urinary incontinence defined according to ICS guidelines and associated with urethral hypermobility. Hypermobility was defined as a Q-tip test $>30^{\circ}$ (our cut-off). Exclusion criteria were $>$ grade II prolapse in any vaginal compartment, previous incontinence surgery, urine retention, neurogenic bladder and psychiatric disorders. The pre-operative work-up included a detailed case history, clinical, neurological and urogynecological examination using the Half-Way system (17), the POP-Q system classification (18), and a pelvic static ultrasound scan. All patients underwent a stress test in the supine position at physiological maximum bladder capacity. Urethral hypermobility was evaluated not only by the Q-tip test but also by perineal ultrasound, which is routinely performed at our Institution. During the scan the distance was measured between the bladder neck and a line at right angles to the pubic bone plane. A cut-off value $>7$ was indicative of a hypermobile urethra (19). Urinary incontinence was classified as recommended by the International Consultation on Incontinence and graded according to the Ingelman Sunderberg classification (20). All patients completed two validated questionnaires on quality of life, i.e. the Urogenital Distress Inventory (UDI-6) and the Impact Incontinence Quality of life (IIQ-7) before surgery, at 3, 6, 12 months postoperatively and then annually. Patient satisfaction was scored by inviting patients to mark the grade of 
satisfaction on a VAS scale from 0-10, on which 10 was maximum satisfaction and zero no satisfaction. Before surgery patients performed a 1-h pad test and completed a bladder diary for three days.

All patients underwent a preoperative urodynamic assessment, which included uroflowmetry, provocative cystometry and urethral profilometry. In accordance with ICS guidelines, filling cystometry was performed in all patients with saline solution at a flow rate of $25 \mathrm{~mL} / \mathrm{min}$ by a double lumen $8 \mathrm{~F}$ catheter (one lumen was used to fill the bladder while the other lumen was connected to a pressure transducer to measure intravesical pressure); a balloon catheter was placed in the rectum to record abdominal pressure. The VLPP was determined at a bladder volume of $200 \mathrm{~mL}$. Patients were instructed to perform several Valsalva maneuvers with a gradual increase in abdominal pressure and urine leakage was recorded as previously described (21). Patients were stratified by VLPP $>60 \mathrm{~cm} \mathrm{H}_{2} \mathrm{O}$ or VLPP $\leq 60 \mathrm{~cm} \mathrm{H}_{2} \mathrm{O}$.

Standard operating techniques were, respectively, the Ulmsten (1) (TVT® - Ethicon) and Delorme techniques (5); no concomitant procedure was performed. The trans-obturator tape was a fusionwelded, non-woven, non-knitted polypropylene tape (Obtape ${ }^{\circledR}$ Mentor-Porges). No preoperative choice between general and regional anesthesia was made. In both procedures, a Foley catheter was always inserted for 24 hours. After the catheter was removed, if post-void residual volume was more than $50 \%$ of bladder volume, intermittent catheterization was proposed. The surgeons were blinded to preoperative VLPP results.

The primary outcome variable was continence status: dry or wet as deduced by clinical examination, stress test and patient interview. Patients were classified in two categories: dry (no leakage during clinical examination and/or stress test and/or reported by patients) vs. wet. Wet patients were then subdivided into "improved" (more than 50\% reduction in incontinence episodes) or "failure". Secondary outcome variables were scores on the quality of life questionnaires and the VAS scale.

Patients were followed-up at 3, 6, 12 months post-operatively and then annually, and at each checkup a blinded assessor measured primary and secondary outcome variables. Terminology followed ICS guideline (8).

VLPP was analyzed retrospectively using data from a randomized controlled study (16) which was accordingly powered. The Mann-Whitney test compared ordinal and non-normally distributed continuous variables. Deviations from Gaussian distribution were checked using the KolgomorovSmirnov test with the Lilliefors method. Categorical data were analyzed by the chi-square test or Fisher's exact test, as appropriate. The level of statistic significance was set at $\mathrm{P}<0.05$. All calculations were carried out with SPSS release 13.0, SPSS Inc., Chicago, USA, 2004.

\section{RESULTS}

Table-1 shows the two groups (TVT vs. TOT) were well balanced demographically. No patient was lost during follow-up. Preoperative urodynamic parameters were similar in the two groups, except for detrusor overactivity, which was more frequent in patients who received TOT (Table-2).

The overall median follow-up was 35 months with a mean follow-up of $32 \pm 12$ months (range 12 55) for the TVT group and $31 \pm 15$ months (range 12 $61)$ for the TOT procedure. 110 patients $(75.9 \%)$ had a follow-up $\geq 24$ months. Table-3 summarizes the operating data. The overall objective cure rates (dry) were $71.4 \%$ for TVT and $77.3 \%$ for TOT. When dry patients were grouped with the "wet but improved" the success rates rose to $90 \%$ and to $90.6 \%$ respectively.

VLPP was $>60 \mathrm{~cm} \mathrm{H}_{2} \mathrm{O}$ in $95 / 145$ patients $(65.5 \%)$. TOT was performed in 50 of these 95 patients $(52.6 \%)$, and in $25 / 50$ patients $(50 \%)$ with VLPP $\leq 60 \mathrm{~cm} \mathrm{H}_{2} \mathrm{O}$. TVT was performed in the others: 45 patients $(47.4 \%)$ with a VLPP $>60 \mathrm{~cm}$ $\mathrm{H}_{2} \mathrm{O}$ and $25 / 50$ patients (50\%) with VLPP $\leq 60 \mathrm{~cm}$ $\mathrm{H}_{2} \mathrm{O}$. The overall objective cure rates were $75.8 \%$ for patients with VLPP $>60 \mathrm{~cm} \mathrm{H}_{2} \mathrm{O}$ and $72 \%$ in patients with VLPP $\leq 60 \mathrm{~cm} \mathrm{H} \mathrm{H}_{2}(\mathrm{p}<0.619)$. No significant differences emerged in objective cure rates when VLPP-stratified patients were matched for TOT or TVT procedures (VLPP > $60 \mathrm{~cm} \mathrm{H}_{2} \mathrm{O}: 82 \%$ TOT vs. $68.9 \%$ TVT; $p<0.172$; VLPP $\leq 60 \mathrm{~cm} \mathrm{H}_{2} \mathrm{O}: 68 \%$ 
Table 1 - Preoperative characteristics of patients.

\begin{tabular}{|c|c|c|c|}
\hline & TVT (70 pts) & TOT (75 pts) & p Value \\
\hline $\operatorname{Age}(y r .)^{*}$ & $61.8 \pm 10.7$ & $60.6 \pm 10$ & NS \\
\hline Parity & $2(0-5)$ & $2(0-4)$ & NS \\
\hline Body mass index $\left(\mathrm{Kg} / \mathrm{m}^{2}\right)^{\circ}$ & $26.9(21.4-39.0)$ & $26.7(19.5-38.0)$ & NS \\
\hline Menopause (n) & 61 & 64 & NS \\
\hline Previous hysterectomy (n) & 27 & 34 & NS \\
\hline Mean duration of SUI (yr.)* & $3.7 \pm 2$ & $4.0 \pm 3.1$ & NS \\
\hline Stress incontinence $(\mathrm{N})$ & 42 & 41 & NS \\
\hline Mixed incontinence $(\mathrm{N})$ & 28 & 34 & \\
\hline \multicolumn{4}{|c|}{ SUI grade - Ingelman sundemberg (N) } \\
\hline Gl & 3 & 8 & \\
\hline G2 & 51 & 54 & NS \\
\hline G & 16 & 11 & \\
\hline Mean Q-tip test & $\begin{array}{l}58.4 \pm 13.5 \\
(\text { range } 45-90)\end{array}$ & $\begin{array}{l}57.9 \pm 14.1 \\
(\text { range } 43-89)\end{array}$ & \\
\hline \multicolumn{4}{|l|}{ Ultrasound measurements } \\
\hline Pad test $(\mathrm{g})$ & $30(0-350)$ & $37.5(0-145)$ & NS \\
\hline Voiding symptoms $(\mathrm{N})$ & 11 & 16 & NS \\
\hline Storage symptoms $(\mathrm{N})$ & 36 & 39 & NS \\
\hline UDI-6 Questionnaire (score) & $8(0-19)$ & $10(2-21)$ & NS \\
\hline IIQ-7 Questionnaire (score) & $8(0-16)$ & $8(0-18)$ & NS \\
\hline Sexually active women(N) & 51 & 50 & NS \\
\hline Dyspareunia $(\mathrm{N})$ & 12 & 16 & NS \\
\hline
\end{tabular}

$T V T=$ tension free vaginal tape $;$ TOT $=$ or transobturator tape $*$ * mean $\pm S D ;$ median and range.

Table 2 - Preoperative urodynamic values (median and range).

\begin{tabular}{lccc}
\hline & TVT $(70 \mathrm{pts})$ & TOT $(75 \mathrm{pts})$ & p Value \\
\hline Maximum cystometric capacity $(\mathrm{mL})$ & $400(170-606)$ & $414(177-630)$ & $\mathrm{NS}$ \\
Opening detrusor pressure $\left(\mathrm{cm} \mathrm{H}_{2} \mathrm{O}\right)$ & $10(1-28)$ & $10(2-35)$ & $\mathrm{NS}$ \\
Maximum detrusor pressure $\left(\mathrm{cm} \mathrm{H}_{2} \mathrm{O}\right)$ & $19(2-99)$ & $18(2-60)$ & $\mathrm{NS}$ \\
Pdet $\mathrm{Qmax}\left(\mathrm{cm} \mathrm{H}_{2} \mathrm{O}\right)$ & $15(1-49)$ & $14(1-58)$ & $\mathrm{NS}$ \\
Qmax $(\mathrm{mL} / \mathrm{sec})$ & $23(5.7-49)$ & $24(9.8-41)$ & $\mathrm{NS}$ \\
MUCP $\left(\mathrm{cm}_{2} \mathrm{O}\right)$ & $39(0-100)$ & $44(11-84)$ & $\mathrm{NS}$ \\
Detrusor overactivity $(\mathrm{N})$ & 4 & 14 & $<0.05$ \\
VLPP & $63(38-89)$ & $66(42-88)$ & $\mathrm{NS}$ \\
Post-void residue $(\mathrm{N})$ & 3 & 5 & $\mathrm{NS}$ \\
\hline
\end{tabular}

$T V T=$ tension free vaginal tape $;$ TOT = transobturator tape $;$ Pdet Qmax = detrusor pressure at maximal flow rate; $M U C P=$ maximum urethral closure pressure; VLPP = Valsava leak point pressure.

TOT vs. $76 \%$ TVT $\mathrm{p}<0.528)$. Data are shown in Table-4. Table-5 reports outcomes in patients with mixed incontinence. No significant difference was observed.
Postoperative changes in questionnaire scores were not significant $(p>0.05)$ when patients were stratified for VLPP and type of procedure. In patients with VLPP > $60 \mathrm{~cm} \mathrm{H}_{2} \mathrm{O}$, the mean post-operative 
Table 3 - Operative data and postoperative morbidity (median and range).

\begin{tabular}{|c|c|c|c|}
\hline & TVT (70 pts) & TOT (75 pts) & p Value \\
\hline Follow-up (months) mean & $32 \pm 12$ & $31 \pm 15$ & NS \\
\hline Median and range & $33(12-55)$ & $34(12-61)$ & \\
\hline Operating time (minutes) & $30(20-60)$ & $20(20-55)$ & NS \\
\hline Hospital stay (days) & $1.5(1-10)$ & $1.3(1-10)$ & NS \\
\hline \multicolumn{4}{|l|}{ Intra-operative complications (N) } \\
\hline Bladder injury & 2 & 1 & \\
\hline Vaginal injury & - & 4 & \\
\hline \multicolumn{4}{|l|}{ Early complications $(\mathrm{N})$} \\
\hline Retropubic hematoma & 1 & - & \\
\hline $\begin{array}{c}\text { Transient voiding dysfunction (urgency, } \\
\text { frequency and nocturia for } 7-10 \text { ) }\end{array}$ & 3 & 2 & NS \\
\hline Transient complete urinary retention & 1 & 1 & \\
\hline \multicolumn{4}{|l|}{ Late complications $(\mathrm{N})$} \\
\hline Vaginal erosion & - & 3 & \\
\hline Voiding dysfunction & $3 \S$ & 3 & \\
\hline Wound discomfort & 1 & - & \\
\hline Foreign body granuloma & $1 * *$ & - & \\
\hline Paraincisional hernia & 1 & - & \\
\hline
\end{tabular}

TVT = tension free vaginal tape $;$ TOT $=$ transobturator tape $; * *=$ removal of suprapubic mesh edges; $\S=1$ patient performed urethrolysis.

scores were 2.24 for TOT and 2.56 for TVT (UDI6) and 1.94 for TOT and 1.93 for TVT (IIQ-7). In patients with VLPP $\leq 60 \mathrm{~cm} \mathrm{H}_{2} \mathrm{O}$, the mean postoperative scores were 2.08 for TOT and 1.36 for TVT (UDI-6) and 1.72 for TOT and 1.52 for TVT (IIQ-7). Table-6 reports mean changes of the questionnaire values. All questionnaire scores were significantly lower than the preoperative value reported in Table $1(\mathrm{p}=0.001)$. Mean post-operative VAS scores were 8.68 for TOT and 8.24 for TVT in patients with VLPP $>60 \mathrm{~cm} \mathrm{H}_{2} \mathrm{O}$ and 7.88 for TOT and 8.44 for TVT in patients with VLPP $\leq 60 \mathrm{~cm} \mathrm{H}_{2} \mathrm{O}(\mathrm{p}=\mathrm{NS})$.

Table 4 - Outcome stratified according Valsava leak point pressure (VLPP) in patients who received TOT or TVT.

Transobturator Tape (TOT)

\begin{tabular}{|c|c|c|c|c|}
\hline & Cured & Failure & Total & p Value \\
\hline VLPP $>60 \mathrm{~cm} \mathrm{H}_{2} \mathrm{O}$ & $41(82 \%)$ & $9(18 \%)$ & $50(100 \%)$ & \\
\hline $\mathrm{VLPP} \leq 60 \mathrm{~cm} \mathrm{H}_{2}^{2} \mathrm{O}$ & $17(68 \%)$ & $8(32 \%)$ & $25(100 \%)$ & \\
\hline Total & $58(77.3 \%)$ & $17(22.7 \%)$ & $75(100 \%)$ & $>0.05$ \\
\hline \multicolumn{5}{|c|}{ Tension Free Vaginal Tape (TVT) } \\
\hline & Cured & Failure & Total & \\
\hline VLPP $>60 \mathrm{~cm} \mathrm{H}_{2} \mathrm{O}$ & $31(68.9 \%)$ & $14(31.1 \%)$ & $45(100 \%)$ & \\
\hline VLPP $\leq 60 \mathrm{~cm} \mathrm{H}_{2} \mathrm{O}$ & $19(76 \%)$ & $6(24 \%)$ & $25(100 \%)$ & \\
\hline Total & $50(71.4 \%)$ & $20(28.6 \%)$ & $70(100 \%)$ & \\
\hline
\end{tabular}

$T V T=$ tension free vaginal tape; TOT = transobturator tape. 
Table 5 - Outcome of patients with mixed incontinence.

\begin{tabular}{|c|c|c|c|c|c|}
\hline \multicolumn{6}{|c|}{ Preoperative Stress Incontinence } \\
\hline Total $=84$ & $\begin{array}{l}\text { Postoperative Results } \\
\text { Dry } 70 \\
\text { Improved } 7 \\
\text { Unchanged } 7\end{array}$ & $\mathbf{T V T}=43$ & $\begin{array}{l}\text { Postoperative Results } \\
\text { Dry }=36 \\
\text { Improved }=5 \\
\text { Unchanged }=2\end{array}$ & $\mathbf{T O T}=41$ & $\begin{array}{l}\text { Postoperative Results } \\
\text { Dry = } 34 \\
\text { Improved }=2\end{array}$ \\
\hline \multicolumn{6}{|c|}{ TVT vs. TOT, $p=$ NS } \\
\hline \multicolumn{6}{|c|}{ Preoperative Mixed Incontinence } \\
\hline Total $=61$ & $\begin{array}{l}\text { Dry } 38 \\
\text { Improved } 16 \\
\text { Unchanged } 7\end{array}$ & $\mathbf{T V T}=27$ & $\begin{array}{l}\text { Dry }=14 \\
\text { Improved }=8 \\
\text { Unchanged }=5\end{array}$ & TOT $=34$ & $\begin{array}{l}\text { Dry }=24 \\
\text { Improved }=8 \\
\text { Unchanged }=2\end{array}$ \\
\hline & & & TVT vs. TOT, p & NS & \\
\hline
\end{tabular}

$T V T=$ tension free vaginal tape $;$ TOT = transobturator tape.

\section{COMMENTS}

The present study seems to indicate preoperative VLPP has no bearing on outcomes after mid-urethral slings as treatment of SUI because when patients were stratified for pre-operative VLPP values we found no difference in cure rates, independently of whether TOT or TVT was used as a treatment or not.

Several authors who used the VLPP to choose treatment in patients with SUI suggested it might provide prognostic information $(12-15,22,23)$. For example, in a series of 43 patients with SUI, O'Connor et al. (15) reported $77 \%$ of patients with a preoperative VLPP $>60$ were cured compared with $25 \%$ of patients with VLPP $\leq 60 \mathrm{~cm} \mathrm{H}_{2} \mathrm{O}$. Rodriguez et al., evaluated 174 patients who underwent distal-urethral sling procedures, dividing them into four groups according to VLPP values (group 1: no leakage; group 2: VLPP $>80 \mathrm{~cm} \mathrm{H}_{2} \mathrm{O}$ group 3: VLPP from 30 to 80; group 4: VLPP $<30)$. Regardless of the VLPP, overall objective cure rates were similar in all groups $(95 \%, 92 \%, 93 \%$ and $92 \%$ respectively) as were patient-reported outcomes and the number of daily pads, even though patients with low VLPP had used more pads per day before surgery (14). These results were confirmed by Cetinel et al. in an investigation into seventy-five consecutive patients with urodynamically proven SUI who underwent TVT (24). When stratified according to preoperative VLPP, 36 patients $(48 \%)$ had $\leq 60$

Table 6 - Mean changes of questionnaire values (basal values minus postoperative values).

\begin{tabular}{lllll}
\hline & TOT & TVT & p Value \\
\hline VLPP> 60 & & & & \\
& UDI-6 & 6.00 & 4.73 & NS \\
VLPP $\leq 60$ & IIQ-7 & 5.60 & 5.60 & NS \\
& & & & NS \\
& UDI-6 & 6.28 & 7.20 & NS \\
\hline
\end{tabular}

$T V T=$ tension free vaginal tape; TOT = transobturator tape. 
cm $\mathrm{H}_{2} \mathrm{O}$ and 39 patients (52\%) had > $60 \mathrm{~cm} \mathrm{H}_{2} \mathrm{O}$. When cure rates were compared with preoperative VLPP, no significant difference emerged at a mean follow-up of 21.6 months (89.7\% vs. $88.9 \%$ respectively). Abdel-Hady investigated the efficacy of tension-free vaginal tape (TVT) in 80 women with a low VLPP $\left(\leq 60 \mathrm{~cm} \mathrm{H}_{2} \mathrm{O}\right)$ in a series of 658 patients (25) and reported an $86 \%$ cure rate (dry) and a $14 \%$ improved rate (wet but improved) at 6 months, concluding that the high efficacy of TVT makes it the first choice treatment for women with SUI - including those with low VLPP.

Although the findings in the present study concur with several reports, one weakness in our study design is the mix of TVT and TOT that could have partly biased results as TOT seems more suitable than retropubic TVT for SUI with urethral hypermobility (26). Secondly, dividing patients arbitrarily into two groups on the basis of a VLPP cut-off of $60 \mathrm{~cm} \mathrm{H}_{2} \mathrm{O}$ may have been a bias. Recently Guerette et al. found that the cut-off values of VLPP $>60 \mathrm{~cm} \mathrm{H}_{2} \mathrm{O}$ and Maximum Urethral Closure Pressure $>40 \mathrm{~cm} \mathrm{H}_{2} \mathrm{O}$ were the most predictive factors of surgical success, showing a sensitivity of $83 \%$ and specificity of $79 \%$ (27).

Although most surgeons recognize that outcome assessment tools are often debatable, the issue assumes marked significance after operations that are designed to decrease the impact of specific signs and symptoms such as incontinence, and outcomes are correlated with preoperative outcome predictors at urodynamics. In the present study we tried to address issues related to outcome after midurethra sling placement and validation of VLPP as an objective parameter for assessing outlet region function using established, generally accepted criteria. However, increasing evidence suggests with urodynamic findings that the patient's condition and specific quality of life could be dissociated (28). Although studies reporting urinary incontinence as outcome and analyzing outcome predicting factors can never develop the level of evidence seen for other symptoms or disease states such as oncologic outcome reporting, investigating pre-operative predictive factors remains mandatory so as to avoid overuse or misuse of mid-urethra slings and improve quality of care.
Minimal requirements for predictor reporting include not only preoperative VLPP as in our case, but also peri-operative complications, hospital stays and length of follow-up data, which seems insufficient in many studies. The 3-year follow-up, which is presented here, may be a step forward in this direction. Finally, we cannot forget the individual's response to surgery for SUI and the impact that other variables have on single outcome criterion, which make it difficult to discuss the pathophysiological significance of the VLPP.

\section{CONCLUSION}

Preoperative VLPP, which was stratified for preoperative VLPP $\left(\leq\right.$ or $>$ of $\left.60 \mathrm{~cm} \mathrm{H}_{2} \mathrm{O}\right)$, was not dependent on outcome after TVT or TOT. Further studies remain mandatory to confirm these data and to investigate other outcome independent variables.

\section{CONFLICT OF INTEREST}

None declared.

\section{REFERENCES}

1. Ulmsten U, Henriksson L, Johnson P, Varhos G: An ambulatory surgical procedure under local anesthesia for treatment of female urinary incontinence. Int Urogynecol J Pelvic Floor Dysfunct. 1996; 7: 81-5; discussion 85-6.

2. Rezapour M, Ulmsten U: Tension-Free vaginal tape (TVT) in women with recurrent stress urinary incontinence-a long-term follow up. Int Urogynecol J Pelvic Floor Dysfunct. 2001; 12 (Suppl 2): S9-11.

3. Nilsson CG, Falconer C, Rezapour M: Seven-year follow-up of the tension-free vaginal tape procedure for treatment of urinary incontinence. Obstet Gynecol. 2004; 104: 1259-62.

4. Jomaa MA: seven-year follow up of tension free vaginal tape (TVT) for surgical treatment of female stress urinary incontinence under local anaesthesia [abstract]. Int Urogynecol J 2003, 14: S69.

5. Delorme E: Transobturator urethral suspension: miniinvasive procedure in the treatment of stress urinary incontinence in women. Prog Urol. 2001; 11: 1306-13. 
6. deTayrac R, Deffieux X, Droupy S, ChauveaudLambling A, Calvanèse-Benamour L, Fernandez H: A prospective randomized trial comparing tension-free vaginal tape and transobturator suburethral tape for surgical treatment of stress urinary incontinence. Am J Obstet Gynecol. 2004; 190: 602-8. Retraction in: Am J Obstet Gynecol. 2005; 192: 339.

7. Miller JJ, Botros SM, Akl MN, Aschkenazi SO, Beaumont JL, Goldberg RP, et al.: Is transobturator tape as effective as tension-free vaginal tape in patients with borderline maximum urethral closure pressure? Am J Obstet Gynecol. 2006; 195: 1799-804.

8. Abrams P, Cardozo L, Fall M, Griffiths D, Rosier P, Ulmsten $\mathrm{U}$, et al.: The standardisation of terminology of lower urinary tract function: report from the Standardisation Sub-committee of the International Continence Society. Neurourol Urodyn. 2002; 21: $167-$ 78.

9. McGuire EJ, Fitzpatrick CC, Wan J, Bloom D, Sanvordenker J, Ritchey M, et al.: Clinical assessment of urethral sphincter function.J Urol. 1993; 150: 1452-4.

10. Feldner PC Jr, Bezerra LR, de Castro RA, Sartori MG, Baracat EC, de Lima GR, et al.: Correlation between valsalva leak point pressure and maximal urethral closure pressure in women with stress urinary incontinence. Int Urogynecol J Pelvic Floor Dysfunct. 2004; 15: 194-7.

11. Albo M, Wruck L, Baker J, Brubaker L, Chai T, Dandreo $\mathrm{KJ}$, et al.: The relationships among measures of incontinence severity in women undergoing surgery for stress urinary incontinence. J Urol. 2007; 177: 18104.

12. Hsieh GC, Klutke JJ, Kobak WH: Low valsalva leakpoint pressure and success of retropubic urethropexy. Int Urogynecol J Pelvic Floor Dysfunct. 2001; 12: 4650.

13. Hutchings A, Griffiths J, Black NA: Surgery for stress incontinence: factors associated with a successful outcome. Br J Urol. 1998; 82: 634-41.

14. Rodríguez LV, de Almeida F, Dorey F, Raz S: Does Valsalva leak point pressure predict outcome after the distal urethral polypropylene sling? Role of urodynamics in the sling era. J Urol. 2004; 172: 210-4.

15. O'Connor RC, Nanigian DK, Lyon MB, Ellison LM, Bales GT, Stone AR: Early outcomes of mid-urethral slings for female stress urinary incontinence stratified by valsalva leak point pressure. Neurourol Urodyn. 2006; 25: 685-8.

16. Porena M, Costantini E, Frea B, Giannantoni A, Ranzoni $\mathrm{S}$, Mearini L, et al.: Tension-free vaginal tape versus transobturator tape as surgery for stress urinary incontinence: results of a multicentre randomised trial. Eur Urol. 2007; 52: 1481-90.

17. Baden WF, Walker T: Grading Support Loss: The Halfway System. In: Baden WF, Walker T (eds.), Surgical Repair of Vaginal Defects. Philadelphia, Lippincott. 1992; pp. 13-23.

18. Bump RC, Mattiasson A, B $\varnothing$ K, Brubaker LP, DeLancey JO, Klarskov P, et al.: The standardization of terminology of female pelvic organ prolapse and pelvic floor dysfunction. Am J Obstet Gynecol. 1996; 175: 107.

19. Pajoncini C, Rosi P, Morcellini R, Costantini E, Mearini E, Guercini F, et al.: Guidelines for endocavity ultrasound scan in SUI and pelvic floor disease. Neurourol Urodyn. 1998; 17: 372-3.

20. Ingelman-Sundberg A, Ulmsten U: Surgical treatment of female urinary stress incontinence.Contrib Gynecol Obstet. 1983; 10: 51-69.

21. Giannantoni A, Di Stasi SM, Cucchi A, Mearini E, Bini V, Porena M: Pelvic floor muscle behavior during Valsalva leak point pressure measurement in males and females affected by stress urinary incontinence. J Urol. 2003; 170: 485-9.

22. Wan J, McGuire EJ, Bloom DA, Ritchey ML: Stress leak point pressure: a diagnostic tool for incontinent children. J Urol. 1993; 150: 700-2.

23. Leach GE, Dmochowski RR, Appell RA, Blaivas JG, Hadley HR, Luber KM, et al.: Female Stress Urinary Incontinence Clinical Guidelines Panel summary report on surgical management of female stress urinary incontinence. The American Urological Association. J Urol. 1997; 158: 875-80.

24. Cetinel B, Demirkesen O, Onal B, Akkus E, Alan C, Can $\mathrm{G}$ : Are there any factors predicting the cure and complication rates of tension-free vaginal tape? Int Urogynecol J Pelvic Floor Dysfunct. 2004; 15: 188-93.

25. Abdel-Hady el-S, Constantine G: Outcome of the use of tension-free vaginal tape in women with mixed urinary incontinence, previous failed surgery, or low valsalva pressure. J Obstet Gynaecol Res. 2005; 31: 3842.

26. Jeon MJ, Chung DJ, Park JH, Kim SK, Kim JW, Bai SW: Surgical Therapeutic Index of Tension-Free Vaginal Tape and Transobturator Tape for Stress Urinary Incontinence. Gynecol Obstet Invest. 2007; 65: 41-46.

27. Guerette NL, Bena JF, Davila GW: Transobturator slings for stress incontinence: using urodynamic parameters to predict outcomes. Int Urogynecol J Pelvic Floor Dysfunct. 2008; 19: 97-102. 
28. Lowenstein L, Dooley Y, Kenton K, Rickey L, FitzGerald MP, Mueller E, at al.: The volume at which women leak first on urodynamic testing is not associated with quality of life, measures of urethral integrity or surgical failure. J Urol. 2007; 178: 193-6.
Accepted after revision:

November 26, 2007

\section{Correspondence address:}

Dr. Massimo Lazzeri

Section of Urology and Andrology

Via Brunamonti 51

06100 Perugia, Italy

Fax: + 390 75 572-6123

E-mail:lazzeri.m@tiscali.it

\section{EDITORIAL COMMENT}

The cure of female stress urinary incontinence should be based on proper patient selection in order to improve the outcome and accurately predict the therapeutic results. Over the years, there have been various proposals for therapy design regarding the existence or absence of overactive bladder concomitantly with stress urinary incontinence, urethral hypermobility or hypomobility, intrinsic sphincter deficiency, etc. The Valsava leak point pressure (VLPP) was previously advocated as an important cure rate predictor for the mid-urethral sling operations,

\section{EDITORIAL COMMENT}

Preoperative urodynamic evaluation is common in women undergoing stress incontinence surgery. Urodynamic observations have been used to confirm the diagnosis of urodynamic stress and this may influence the surgeon to elect other operations, such as one of the tension free vaginal tape (TVT) like ones. This might lead the patient to lose the overall TVT benefits and suffer some of the previously used operative modalities. This study evaluates the real value of the VLPP for the prediction of success rate with both TVT and transobturator tape (TOT), with clear and objective tools. Even though being retrospective, the additional information provided here for the urogynecologist practitioner makes the selection of operations for patient free of bias.

Dr. M. Neuman Urogynecology, Department of Gynecology Shaare Zedek Medical Center Ben-Gurion University of the Negev Jerusalem, Israel E-mail:neuman@szmc.org.il

incontinence (USI) by observing transurethral urine loss at the moment of increased abdominal pressure in the absence of a detrusor contraction. In addition to this general diagnostic finding, urodynamic criteria 
are also used to inform surgical decision-making. The concept of intrinsic sphincter deficiency (ISD) or type III incontinence was introduced by McGuire to characterize a urethra that no longer has a functioning sphincter (1). Commonly used measures to evaluate urethral sphincter integrity are Valsalva leak point pressure (VLPP) and maximal urethral closure pressure (MUCP); low values have been associated with poor surgical results. Previous studies have demonstrated a higher failure rate of the Burch procedure in patients with a MUCP lower than $20 \mathrm{~cm}$ $\mathrm{H}_{2} \mathrm{O}(2,3)$. This cut off value of $\mathrm{MUCP} \leq 20 \mathrm{~cm} \mathrm{H}_{2} \mathrm{O}$ has been used arbitrarily as an indicator for ISD. Other reports have evaluated sphincter function on the basis of the VLPP, the lowest abdominal pressure to cause urinary leakage as recorded during a slowly performed Valsalva maneuver. In the original report by McGuire et al. (4), the VLPP was performed with the patient standing under fluoroscopy. Their results demonstrated that $75 \%$ of patients with type III incontinence had a low VLPP. A low VLPP less than $60 \mathrm{~cm} \mathrm{H}_{2} \mathrm{O}$ was thought to be associated with type III incontinence, which is characterized by an open bladder neck at rest and an immobile urethra with proximal damage (5).

The value of urethral sphincter functioning as a predictor for the success rate of tension free vaginal tape (TVT) and transobturator tape (TOT) is controversial (6-8). Most published studies have a small number of participants and are under-powered (6-8). Dr. Costantini and her group should be commended for attempting to answer a clinically relevant question regarding the prognostic value of VLPP for the success of midurethral slings. The presented study is an ancillary part of a randomized study which compared TVT vs. TOT for treatment of stress urinary incontinence (9). All patients underwent standardized multi-channel urodynamic testing prior to the surgery. VLPP values were obtained at a bladder volume of $200 \mathrm{~mL}$. The patients were randomized to either TVT or TOT irrespective of the urodynamic results. Overall there were no differences in the cure rate of patients who had VLPP $\leq 60 \mathrm{~cm} \mathrm{H}_{2} \mathrm{O}$ to those who had VLPP $>60 \mathrm{~cm} \mathrm{H}_{2} \mathrm{O}$. A major limitation of this study is the relatively narrow distribution and low median VLPP of the participants. The median values for TOT and
TVT were 61 and $66 \mathrm{~cm} \mathrm{H}_{2} \mathrm{O}$ respectively. Since a VLPP around $60 \mathrm{~cm} \mathrm{H}_{2} \mathrm{O}$ is regarded as low, the authors might have found more significant differences in a group of patients with a wider distribution of VLPPs. In addition, further evaluation of the recorded MUCP data as it relates to surgical cure rates could also be useful. In summary, the ability of urodynamics to predict the success of SUI surgery is not yet fully recognized and more studies are needed to elucidate the role of preoperative urodynamics.

\section{REFERENCES}

1. McGuire EJ, Woodside JR, Borden TA, Weiss RM: Prognostic value of urodynamic testing in myelodysplastic patients. J Urol. 1981; 126: 205-9.

2. Bowen LW, Sand PK, Ostergard DR, Franti CE: Unsuccessful Burch retropubic urethropexy: a casecontrolled urodynamic study. Am J Obstet Gynecol. 1989; 160: 452-8.

3. Quadri G, Magatti F, Belloni C, Barisani D, Natale N: Marshall-Marchetti-Krantz urethropexy and Burch colposuspension for stress urinary incontinence in women with low pressure and hypermobility of the urethra: early results of a prospective randomized clinical trial. Am J Obstet Gynecol. 1999;181: 12-8.

4. McGuire EJ, Fitzpatrick CC, Wan J, Bloom D, Sanvordenker J, Ritchey M, Gormley EA: Clinical assessment of urethral sphincter function. J Urol. 1993; 150: $1452-4$.

5. Blaivas JG, Olsson CA: Stress incontinence: classification and surgical approach. J Urol. 1988; 139: 727-31.

6. O'Connor RC, Nanigian DK, Lyon MB, Ellison LM, Bales GT, Stone AR: Early outcomes of mid-urethral slings for female stress urinary incontinence stratified by valsalva leak point pressure. Neurourol Urodyn. 2006; 25: 685-8.

7. Bai SW, Jung YH, Jeon MJ, Jung DJ, Kim SK, Kim JW: Treatment outcome of tension-free vaginal tape in stress urinary incontinence: comparison of intrinsic sphincter deficiency and nonintrinsic sphincter deficiency patients. Int Urogynecol J Pelvic Floor Dysfunct. 2007; 18: 1431-4.

8. Miller JJ, Botros SM, Akl MN, Aschkenazi SO, Beaumont JL, Goldberg RP, Sand PK: Is transobturator tape as effective as tension-free vaginal tape in patients with borderline maximum urethral closure pressure? Am J Obstet Gynecol. 2006; 195: 1799-804. 
9. Porena M, Costantini E, Frea B, Giannantoni A, Ranzoni S, Mearini L, Bini V, Kocjancic E: Tension-free vaginal tape versus transobturator tape as surgery for stress urinary incontinence: results of a multicentre randomised trial. Eur Urol 2007;52:1481-1491.

Dr. Lior Lowenstein

Division of Female Pelvic Medicine

\& Reconstructive Surgery

Dep. of Obstetrics \& Gynecology and Urology

Loyola University Medical Center

Maywood, Illinois, USA

E-mail:llowenstein@lumc.edu

\section{EDITORIAL COMMENT}

The current study, "Preoperative Valsava Leak Point Pressure May Not Predict Outcome of Mid-Urethral Slings. Analysis from a Randomized Controlled Trial of Retropubic versus Transobturator Mid-Urethral Slings" by Costantini et al is a well designed, randomized controlled trial attempting to address a valuable clinical issue.

Overall, the use of a trans-obturator approach (TOT) for mid-urethral sling can minimize the risk of injury to the lower urinary tract. It has been found to be equally efficacious compared to the retropubic approach (TVT) in the management of stress urinary incontinence for patients with normal urethral function. If this were also true for patients with poor urethral function, or intrinsic sphincteric deficiency (ISD), universal use of the trans-obturator approach may be preferable.
However, the current study must be evaluated critically, and its potential flaws recognized. The optimal definition of ISD is disputed. Many clinicians prefer the use of static maximum urethral closure pressure (MUCP); studies have shown a wide discrepancy between MUCP and VLPP. Additionally, the study is underpowered. With only 50 patients in the ISD group, and an $8 \%$ difference in objective cure with TVT showing superiority, any definitive conclusions cannot be reached.

The authors' study is a valid first attempt to address a vital clinical issue in how best to triage and manage our at-risk patients undergoing antiincontinence surgery. Though the universal use of the potentially lower-risk TOT may indeed prove true, the practice warrants further study before being widely adopted.

\section{Dr. Kenneth Powers}

Associate Professor Obstetrics \& Gynecology Albert Einstein College of Medicine

Chief of Urogyneocology Montefiore Medical Center Bronx, New York, USA E-mail: hoppowers@aol.com 